\title{
52. A New Carboniferous Trilobite from Nagasaka, Iwate Prefecture and its Bearings on Taxonomy and Biogeography*)
}

\author{
By Teiichi Kobayashi, M. J. A., and Koichi TaCHIBANA**)
}

(Communicated June 15, 1978)

Trilobites have long been known to occur in the Lower Carboniferous Karaumedate formation in Nagasaka Area (Tachibana, 1952, $1963)$, but as yet they remained undescribed. In spite of great difficulty due to their crude deformation, the authors reached to the conclusion that the common form at Minami-Iwairi***) of the area reveals a new species of Conophillipsia. Quite unexpected is that its thorax is composed of ten, instead of nine segments, because the genus has been located variously in the Phillipsidae (Roberts, 1963), Crassiproetinae (Osmolska, 1970), and the Phillipsinae (G. and R. Hahn, 1972). Now it is found to be one of the latest survivors of the Proetinae, although it is fairly well isolated from Pudoproetus in the multisegmented pygidium. At the same time it is noteworthy that the find of this Tournaisian genus in Japan suggests the Mongolian geosyncline (Kobayashi, 1971) to be more probable than the Tethyan one for its trans-Asiatic route of migration, because it was thrived in Turkestan and the Kirghiz steppe but so far it is unknown from South Asia.

Family Proetidae, Subfamily Proetinae

Genus Conophillipsia Roberts, 1963, em.

Diagnosis:-Isopygous proetoids having subovoid or trapezoid glabella relatively broad and gently convex; two or three lateral furrows present; preglabellar field absent; eyes medium sized, close to glabella in posterior to middle of cephalon; facial sutures moderately divergent forward from eyes; interpleural furrows absent in thorax and pygidium ; axial rings 13 to 20 and pleural ribs 9 to 15 in pygidium; its marginal border narrow and depressed; test generally granulose.

Type-species :-Conophillipsia brevicaudata Roberts, 1963, from upper Tournaisian, New South Wales, Australia.

Remarks:-The type-species is represented by two cranidia and some free cheeks, thoracic segments and pygidia. In the holotype the

\footnotetext{
Studies on Japanese Trilobites and Associated Fossils-XIII.

**) Faculty of Education, Iwate University, Morioka, Iwate.

***) 岩手県東磐井郡東山町南磐井里
} 
glabella is oval, but trapezoidal in the other. Unfortunately little is known of the occipital lobes and fixed cheeks of the species. Because Roberts referred Phillipsia woodwardi Etheridge, 1892 (Low. Carbon. Queensland), P. kazakensis Weber, 1937 and P. labrosa Weber, 1937 (Low. Tournais. and Passage beds, Turkestan and Kirghiz steppe) to the genus, information may be available from them.

Etheridge's species was revised by Mitchell (1918) with additional material. According to him "Glabella subquadrate, wide and mildly rounded in front,- - three pairs of glabellar furrows present,basal pair (of lobes) subpiriform,--supplementary lobes present (on neck ring)," and "Facial sutures anteriorly directed outward at angle of $25^{\circ}$," and "genal angle apparently blunt."

Weber (1973) proposed Phillipsia labrosa and P. kazakensis respectively for the cephalon and pygidium supposed to belong to a single species. As they occur in abundance, he distinguished their varieties. In the cephalon the glabella is parabolic, separated from the striated frontal border by a deep furrow; basal lobes sharply bounded by posterior furrows; two anterior furrows weak; lateral lobes absent, but a median spine may be present on neck ring; anterior branches of facial sutures slightly divergent forward; genal spine long. Proetus pila which is now referred to Pudoproetus was its common associate closely allied to it, but the cephalon was highly convex, neck ring had triangular lobes at the ends and often a median tubercle; genal spine absent.

In comparison with Proetus missouriensis Shumard he combined this cephalon with the broad paucisegmented pygidium having double pleural ribs in his Proetus pila. As the result the longer and multisegmented pygidium having simple ribs in a greater number which was called Phillipsia kazakensis was supposed to be united with the cephalon of $P$. labrosa.

The above species of Conophillipsia were all represented by dismembered carapaces. Therefore it is of great importance to find the complete dorsal shield of the genus. Remarkably enough, its thorax is composed of ten, instead of nine segments. This number combined with the short forwardly tapering glabella excludes the genus out of the Phillipsinae. Insofar as the cephalon is concerned, it is undeniable that the nearlest allay to this genus is Pudoproetus to which $P$. pila and $P$. missouriensis belong.

Pudoproetus and Conophillipsia are evidently two distinct genera, because the former is heteropygous whereas the latter is isopygous. If compared to the former, the pygidium is relatively long in the latter. It has 6 to 10 axial rings and 5 to 8 pleural ribs in Pudoproetus and 13 to 20 rings and 9 to 15 simple ribs in Conophillipsia. The marginal 
border is well developed in the former and narrow and ill-defined in the latter.

Though the dorsal shield is more inflated in Pudoproetus than Conophillipsia, both of them are decisegmented in thorax and their tests commonly granulate. Their cephala are similar to each other, but in Pudoproetus' cephalon the glabella is suboval, highly convex and overhanging the frontal border; lateral furrows in three to four pairs, instead of two to three pairs in Conophillipsia; occiptal lobes ill-defined on neck ring; tropidial crest present in typical cheek; anterior branches of facial sutures less divergent than in Conophillipsia.

Conophillipsia resembles Crassiproetus Stumm, 1953 and Monodechenella Stumm, 1953, particularly in the pygidium, but the glabella is oval and strongly convex in them and the glabellar furrows are all obsolete in the former and so in the latter except for the posterior pair. The occipital lobe is absent in the former, but present in the latter. The pleural furrows are present in thorax in these two genera. Their resemblances indicate probably their subparallel specialization to Conophillipsia. Cyrtoproetus quite disagrees with this genus in the elongate and constricted glabella and other characteristics of the pygidium. Conophillipsia would be an aberrant off-shoot from the Proetinae stock near Coniproetus or Bohemiproetus.

Distribution:-Lower Carboniferous, Tournaisian to Etroeungtian; Australia (Queensland and New South Wales), Eastern and Central Asia (Japan, Kirghiz Steppe and Turkestan).

Additional species are Proetus meisteri Weber, 1937, P. antonovi Weber, 1937, and Proetus cervicontinens Weber, 1937 (Osmolska, 1970).

Conophillipsia decisegmenta, sp. nov.

Description:- Dorsal shield elliptical, moderately inflated. Cephalon nearly semicircular, surrounded by marginal border and furrow; genal spine short; glabella more or less trapezoidal, most expanded laterally through basal lobes; three pairs of lateral furrows distinct; posterior furrow diagonal, isolating basal lobes and issuing a short branch adaxially from midway; middle furrow less inclined; anterior one subhorizontal; unfurrowed median part broader than lateral lobe; frontal lobe a third as long as glabella; occipital furrow nearly straight; occipital ring depressed, provided with a pair of occipital lobes; eyes close-set to glabella in the extent from middle lateral lobe to posterior half of basal lobe; facial sutures divergent diagonally from eyes, but suddenly recurving on marginal border; the suture running also diagonally behind eye to cut posterior cheek border near its middle point; coarse granules distributed on cephalon 


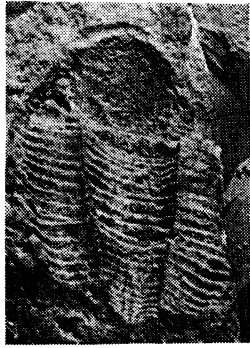

lb

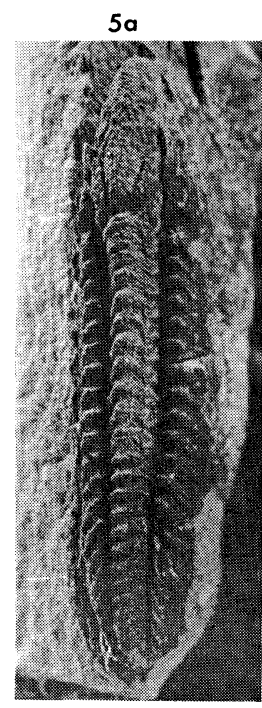

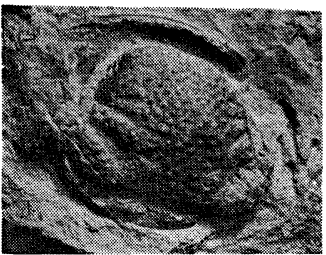

2
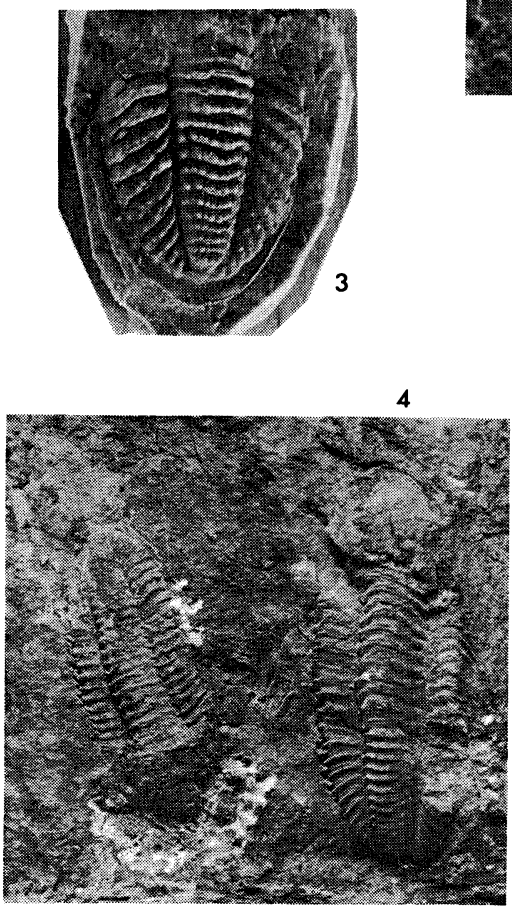

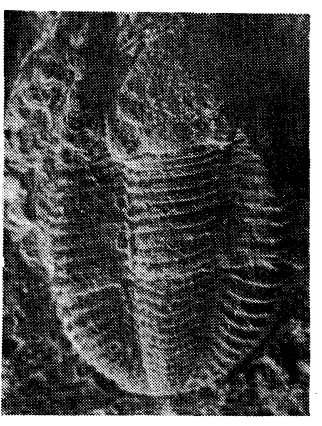

la

Figs. 1-4. Conophillipsia decisegmenta, sp. nov. 1, a-b: Dorsal shield, holotype, internal and external moulds. $\times 1 \frac{1}{3} .2$ : Cranidium, paratype, internal mould. $\times 2$. 3: Pygidium, paratype, rubber cast from external mould. $\times 1 \frac{1}{3}$. 4: Two dorsal shields, paratypes, internal moulds. $\times 1 \frac{1}{3}$.

Fig. 5. Conphillipsia cf. decisegmenta. a-b: Dorsal shield, strongly deformed. Internal mould, $\times 1 \frac{1}{3}$ and external mould, $\times 2$.

particularly densely on glabella.

Thorax composed of ten segments; axial lobe slowly narrowing backward, but almost as wide as pleural lobe; pleural furrow very weak or obsolete. In pygidium axial lobe tapering back rather rapidly and rounded off at end, composed of 14 rings and terminal piece; pleural field divided into 11 to 12 ribs by deep furrows, arching down near margin; marginal border narrow and depressed; marginal furrow very weak or absent. Granulation of test more developed on axial than pleural lobe, obscure on marginal border and absent on various furrows. 
Observation:-Because the specimens before hand are all deformed in different directions and various degrees, it is difficult to say any exact proportion in length among the cephalon, thorax and pygidium or in breadth between the axial and pleural lobes, but nevertheless it is certain that the thorax is nearly parallel-sided and the cephalon and pygidium are similar to each other in size and outline.

It is noteworthy that the glabella is neither longiconic nor pearshaped. Because of the posterior expansion it looks somewhat oval, but the frontal lobe is so broad that the glabellar outline takes rather trapezoid. The eyes are medium in size. In a paratype cranidium (Fig. 2) the narrow and high frontal rim is separated from the glabella by a well developed trough.

In the holotype dorsal shield (Fig. 1, a-b) which is somewhat shortened secondarily in the sagittal trend, the cephalon and pygidium are semicircular. Two shields (Fig. 4) which are a little laterally compressed, have pygidia parabolic in outline. A well preserved pygidium (Fig. 3) is similar to them. Its marginal border is comparatively broad. The axial lobe is composed of 14 rings and a depressed small subtriangular terminal piece and the pleural lobe is divided into 11 simple ribs beside the anterior band of the first segment by pleural furrows. The rings and ribs are each provided with a row of nodes along the posterior margin which are 12 or more in number on some anterior rings. The granulation is lessened on the thorax and pygidium than the cephalon and so on the pleural lobe than the axial lobe.

In a dorsal shield (Fig. 5, a-b) strongly compressed laterally the glabella is crudely twisted. As the result it is invaded into the preglabellar furrow and rounded in front. Nevertheless, it belongs probably to this species, because the three lateral glabellar furrows, occipital lobes, size and position of eyes, ten thoracic segments, the segmentation of the pygidium and the granulate test are all diagnostic of this species. It shows the facial suture and genal spine clearly.

Occurrence:-All from clayslate of Minami-Iwairi.

\section{References}

Hahn, G. and R.: Trilobitae carbonici et parmici III. Fossilium Catalogus I. Animalia, Pars 120, 336-351.

Kobayashi, T. (1971): The Manmo Group of the Mongolian Geosyncline in Manchuria and Adjacent Areas. Geology and Mineral Resources of the Far East, Univ. of Tokyo Press, vol. 3, pp. 3-69.

Kobayashi, T., and Hamada, T. (1978): On the relationship of Carboniferous trilobites between Australia and Eurasia. Proc. Japan Acad., 54B, 96-100.

Mitchell, J. (1918): The Carboniferous trilobites of Australia. Proc. Linn. Soc. N. S.W., 43, 437-492, pls. 46-53.

Osmolska, H. (1970) : Revision of non-cyrtosymbolinid trilobites from the Tour- 
naisian-Namurian of Eurasia. Paleontol. Pol., no. 23, 1-165, pls. 1-22.

Roberts, J. (1963) : A Lower Carboniferous fauna from Lesinsbrook, New South Wales. J. Proc. Roy. Soc. N. S. W., 97, 1-20, pls. 1-6.

Tachibana, K. (1951): On the Tobigamori group of the Nagasaka district, Kitakami Mountainland. J. Geol. Soc. Japan, 58, 353-360, 445-455.

(1963) : Upper Devonian and lowest Carboniferous formations in the vicinity of Minami-iwairi, Higashiyama-machi, Iwate Prefecture, Pt. 1. Bull. Fac. Lib. Arts, Nagasaki Univ. Nat. Sci., 4, 31-43.

Weber, V. N. (1937): Trilobites of the Carboniferous and Permian systems of the U.S.S.R. I. Carboniferous trilobites. Monogr. Paleont. USSR, 71(1), 1159, pls. 1-11. 